\title{
Carry out research experiments teaching to train students innovation capability
}

\author{
Song fuyuan 1 \\ Coll Power \& Energy Engn, \\ Harbin Engn Univ, \\ Harbin, Heilongjiang Pr, China \\ e-mail:songfuyuan@hrbeu.dedu.cn
}

\author{
yu jing 2 \\ Coll Power \& Energy Engn, \\ Harbin Engn Univ, \\ Harbin, Heilongjiang Pr, China \\ e-mail: 741962165@qq.com
}

\author{
Zhang guolei 3 \\ Coll Power \& Energy Engn, \\ Harbin Engn Univ, \\ Harbin, Heilongjiang Pr, China \\ e-mail: zhangguolei@hrbeu.cedu.cn \\ Li yanjun 4 \\ Coll Power \& Energy Engn, \\ Harbin Engn Univ, \\ Harbin, Heilongjiang Pr, China \\ e-mail: liyanjun@hrbeu.edu.cn
}

\begin{abstract}
The research teaching can make students obtain relaxed environment of discovering the world and exploring the world, provide time and space to research questions and stimulate innovation and the desire in the learning process. Research experiment teaching is a student-centered teaching mode, it is the implementation of the educational process while studying edge research edge practice, witch taking the student as the main body. Research experiment teaching can cultivate students' practice, research and cognitive ability, innovation consciousness and creative ability, can effectively promote the all-round development of students' comprehensive quality.
\end{abstract}

Keywords- Research experiment teaching; innovation consciousness; comprehensive quality

\section{INTRODUCTION}

21st century society has entered the era of knowledge economy, economic globalization, resources information, knowledge and information on the height of cross-linking, social spirit of innovation have made unprecedented demands on workers. The key of Innovation is personnel, the training of personnel rely on education. However, for a long time in China at all levels of education are more focused on knowledge transfer, especially teachers' individual irrigation conveyance book knowledge, teaching mode of students ' knowledge of passive acceptance. This training model has hindered the cultivation of students' innovative consciousness and innovative ability, seriously affecting the growth of our creative talents. Therefore, changing concepts of education, emphasis on innovative education, has become an urgent task in China's education reform. The mode of cultivation of innovative talents teaching research teaching. Research learning and traditional learning are very different, it raised quickly become a hot spot of the education of many experts and scholars.

\section{THE CONNOTATION OF THE RESEARCH EXPERIMENT TEACHING}

Research experiment teaching includes not only for students to develop the inquiry learning all kinds of teaching activities, including college students' research and innovation activities, it puts forward the challenge, to the nanny the traditional teaching mode of experiment of the verification experiment primarily. According to the study, research and practice of the organic combination of teaching and research the connotation of innovative education requirements, set up the new teaching mode of the "binary system research skills training". Course is divided into two stages of basic comprehensive experiment (including basic theory) and the research experiment teaching. Through the research experiment, students earned the basic scientific research method and process, won the good opportunity to practice their research idea, and get the exercise of the selecting experimental subject, designing, preparation, implementation and results arrangement of the experiment, writing thesis, the respondent and many other link. The research papers of experiments of students to write is expression specification, complete, clear thinking, logical, and very high quality , some paper has been published on the country, two academic journals , on domestic and international academic conference. By research teaching, the students in the learning process get a discovered the world, explore the world comfortable environment, to provide research problems of time and space, arouse the desire of innovation. Research-oriented teaching is effective teaching mode of cultivating creative talents. The research teaching students in the learning process to discover the world, to explore the world relaxed environment, to provide time and space research questions to stimulate innovation and the desire.

\section{NECESSITY OF DEVELOPING RESEARCH-ORIENTED EXPERIMENT TEACHING}

Currently there are three issues on the education experiment teaching. First, to verify the experiment-oriented teaching, focusing on mastery of knowledge and skills acquisition, ignore the issue of training of research ability and problem-solving skills, cognitive abilities, neglect of cultivation of students' innovation ability; Second, out of step with the production of teaching, new technologies, new knowledge is not reflected in a timely manner; Third, 
ignoring students first-hand experience, there is no importance to the improvement of students ' practical ability. the existence of these three issues, the reform demands placed on experimental mathematics.

The research experiment teaching based on students' development for this teaching mode, it take the student as the main body. Experimental teaching research is based on the development of students teaching mode to the student as the main body, the implementation of the educational process "while learning, research, practice". It educates the ability of student's practice, research and cognitive, emphasizes to improve the sense of innovation and creativity and can effectively promote the comprehensive development of the overall quality of students. Experimental teaching research from the selection issues, design, development and utilization of resources to the exploration and study conclusions, give the students a great deal of the initiative, which fully reflects the autonomy of students, provide a space for students to maximize the development of innovative thinking and practical ability. It is more concerned about the students' learning process, and concern for the students would be able to have a choice to judgment, interpretation, application on the knowledge, which has been found to create something new, and to develop creative ideas. At the same time, the research experiment teaching course evaluation is also thoroughly, diversity and flexibility, can let the student fully experience as long as there is pay, you will be able to achieve success of pleasant sensation, which helps to improve the students' interest in learning, scientific research, reduce the bondage of teachers and students, so as to fully dig out the students' academic ability and learning potential, help create ability and application ability into full play.

Experimental teaching research fully reflects the subjectivity found success principles of education, through the teaching of all parties interaction, to cultivate students' ability to develop and explore ability, to develop students' potential ability. Interactive parties through teaching students to develop the ability to explore the ability to develop students' potential ability. It to broaden the course and course especially "integration" education is especially useful. At the same time, this pattern also contributed to the transformation of teaching evaluation by the emphasis on teaching results of importance to the application of knowledge.

\section{THE PLANNING PRINCIPLE RESEARCH OF EXPERIMENTAL TEACHING CONTENT}

\section{A. Experimental content integrated, practical and personalized}

The opening of the experiment content on the one hand manifests in the content, method, design, the teacher puts forward problems to be solved and the corresponding material, on the other hand, for the performance of the experiment in the process to have many inquiry activity, the class introverted extracurricular activities, such as open space from real life, production practice looking for the subject, etc. Many of the specific content (material, procedures, methods, etc.) in the teaching process should not be hard and fast rules, the students' free play, the flexibility and this will help the research experiment, helps the student to form the divergent thinking, helps to cultivate students' innovative ability. Experimental contents reflect the teaching purpose and determine the effect of experiment. At the same time in the content of the choice is not only to ensure the double-base traditional advantages, but also pay attention to the students' interest and student development needs, which fully reflects with the students as the main teaching method, train the student to have the will to learn, will find, will explore, comprehensive analysis and judgment, expression, will use knowledge to solve the question ability.

\section{B. Diversification of the type of experiment}

The experimental teaching should comply with the students' cognitive regularity and practical level, the student learning should not only have to accept type of study, also want to have inquiry learning, organic combination of both to students knowledge and learning experience to obtain is complete. The experimental arrangement should be implemented progressively, from simple to comprehensive, and can mobilize the enthusiasm and initiative of the students' learning. That is to establish the research experiment teaching dominant position at the same time, also cannot ignore the role of experiment. The experimental teaching consists of two components: validation type test and research experiments. Verification type the basis of the experimental teaching contents, through the basic experiment teaching and cultivating students' basic experiment skills, master the method of operation, data processing and the ability of the expression. The research experiments are mainly three forms of comprehensive and designing experiments, as well as topics .the student through the research experiment, look carefully at the experiment phenomena are the analysis judgment, logic reasoning, scientific design the plan and make a conclusion and acquisition and processing information ability, etc. Students through research experiments, carefully observed experimental phenomena analysis and judgment, logical reasoning, scientific experimental design, conclusions as well as to obtain and process information the ability. It pays attention to the process and the cultivation of innovative ability.

\section{RESEARCH TEACHING MODE}

It will to give students learning-oriented before each class, and to put forward the literature reviewing requirements, preparation and design experiment each record, charts and statistics methods, the results of prediction and correlation theory. In the process of class teaching, experiment, combined with discussion. Teachers through the form of lectures to introduce students to the dynamic and direction of a particular field of study, the student literature and 
experimental design, opening report and discuss, comprehensive everybody's research approach, forming a more scientific and feasible research approach experiment trial test and experimental research, and finally by the students research summary report and thesis defense. The research teaching throughout the teaching process, and create a good atmosphere of academic research. Students' experimental report reached a higher quality, the research paper reached a higher level. Research-based learning mode mades the students in the learning process get a discovered the world, explore the world comfortable environment, to provide research problems of time and space, arouse the desire of innovation. Research-oriented teaching is effective teaching mode of cultivating creative talents.

\section{CONCLUDING REMARK}

Experiment Teaching Reform is the soul of experimental teaching work, how to play the role of experiment teaching, better to cultivate talents with high quality service, is a very important issue, as well as a systematic project.
There are many ways to be a research - oriented experiment teaching innovation and reform, perseverance and intensive work required to make truly achieve the research - oriented experiment teaching reform to improve students' comprehensive quality and ability.

\section{REFERENCES:}

[1] Bernat, A. Structuring the student research experience. SIGCSE Bulletin, v 32, n 3, Sept. 2000, p 17-20

[2] Gates, Ann Q. Meeting the challenge of expanding participation in the undergraduate research experience. Proceedings - Frontiers in Education Conference, v 3, 1998, p 1133-1138

[3] Zhou dehui .Offering exploratory experimental courses to develop students creative abilities[J]. Research and explorat ion in laborat ory. 2005, (12) : 67-69

[4] Wu qunying, huang qinni, Dong keqi. Deepen the reform of practice teaching to cultivate students' innovation spirit and practice ability[J]. Experimental technology and management, 2005, 22(9) : 1-3、10

[5] Meng Qinfan. Cultivation of innovat ive tlents by exploratory experiments[J]. Research and explorat ion in laborat ory. ,2004, (1) : 85-88 